\title{
(2) OPEN ACCESS \\ Factors related to road system organisation and its association with mortality due to motor vehicle- pedestrian collisions in Guadalajara Metropolitan Area
}

\author{
Melva Guadalupe Herrera-Godina, ${ }^{1}$ Berenice Martínez-Melendres, ${ }^{2}$ \\ Hiram René Novelo-Ramírez, ${ }^{2}$ Julio Cesar Dávalos-Guzmán, ${ }^{3,4}$ Alfredo Celis, ${ }^{5}$ \\ Guillermo González-Estevez, ${ }^{2}$ Ana Cecilia Mendez-Magaña (D) 5,6
}

\begin{abstract}
'Psicología Aplicada, Universidad de Guadalajara, Guadalajara, Mexico ${ }^{2}$ Doctorado en Ciencias de la Salud Pública, Universidad de Guadalajara, Guadalajara, Mexico

${ }^{3}$ Salud Poblacional, Universidad de Guadalajara, Guadalajara, Mexico

${ }^{4}$ Departamento de Investigación y Epidemiología, Secretaria de Salud de Jalisco, Guadalajara, Mexico

${ }^{5}$ Publich Health, University of Guadalajara, Guadalajara, Mexico

${ }^{6}$ Unidad de Medicina Familiar No 53, Epidemiologia, Instituto Mexicano del Seguro Social, Zapopan, Mexico
\end{abstract}

Correspondence to Dr Ana Cecilia Mendez-Magaña, Salud Pública, Universidad de Guadalajara, Guadalajara 44340, Mexico; dracmm@ yahoo.com.mx

Received 16 January 2019 Revised 25 April 2019 Accepted 29 April 2019 Published Online First 3 June 2019

\begin{abstract}
Introduction Traffic events are one of the five leading causes of mortality in Mexico. Pedestrians are one of the main road users involved in such incidents and have the highest mortality rate, which is regularly analysed in relation to vehicles and pedestrians, but not the built environment. The purpose of this study was to analyse the elements of the road system organisation that influences the mortality rate of pedestrians hit by motor vehicles in the Guadalajara Metropolitan Area.

Method We designed a case and control study in which the cases were sites where a pedestrian died during 2012. The controls were sites close to where the death occurred, as well as those with road infrastructure characteristics similar to those where the events took place. We obtained the pedestrian data from the death certificates and assessed some of the environmental elements of the road sites. A logistic regression analysis was used to estimate OR; $95 \% \mathrm{Cl}$.

Results Road system factors related with pedestrian mortality in close locations were: the presence of bus stops on intersections in one street or both, and road system features, such as the presence of traffic islands, vehicle flow and pedestrian flow.
\end{abstract}

Conclusions According to the urban network theory and multiple theory, the final elements resulted as risk factors due to a fault in connectivity between the nodes. A temporal analysis of urban features will help urban planners make decisions regarding the safety of pedestrians and other road users.

\section{BACKGROUND}

Studies on transit events in which pedestrians are injured by a motor vehicle have generally focused on features surrounding the pedestrian, motor vehicle and driver involved. Thus, the environment, and the road infrastructure in particular, are two of the least studied aspects.

In Mexico, 16179 deaths by transit events were registered in 2016. This placed transit events as one of the five leading causes of death nationwide. ${ }^{1}$ In the last decade, the state of Jalisco has been placed as one of the three states with the highest mortality rate. Specifically, Guadalajara Metropolitan Area (GMA) accounted for the $58 \%$ of the state deaths. ${ }^{23}$
This work is based on three theories that help explain the built environment. The first of these theories is the urban network theory, ${ }^{4} 5$ which explains the complex organisation of space by assessing structural elements and their functions through interfering elements, nodes, connections and hierarchies. ${ }^{6-8}$ Second, graph theory and probability establish the necessary means to measure road systems. Next, the functionality of these systems is analysed through the complex network theory; specifically, this part of the analysis focuses on the sites where motor vehicle-pedestrian collisions have taken place and caused fatalities. ${ }^{8}$

Similar studies had been conducted in countries such as Canada, the USA, New Zealand and the UK, among others. However, the road system of any of these countries differs from GMA; hence, the interest of this study is to analyse the elements of road systems that impact mortality due to motor vehicle-pedestrian collisions in GMA.

\section{MATERIALS AND METHODS}

A case-control study was conducted in which the cases were intersections with registered fatalities due to motor vehicle-pedestrian collisions, with the event occurring between 1 January and 31 December 2012. Controls were those intersections of GMA without fatalities due to motor vehiclepedestrian collisions during 2012.

We calculated the sample size based on the pedestrian risk of dying when crossing a road without using the pedestrian bridge, estimated as OR $>5.0$, a proportion of $5.56 \%$ of controls with exposition and of $25.00 \%$ in cases with exposition, with a confidence level of $95 \%$, a power of $80.00 \%$ and a rate of control by case of $1: 1$. We obtained a minimum sample of 63 cases and 63 controls.

The inclusion criteria for the study cases were intersections where pedestrians from 18 to 65 years old died due to collisions involving a motor vehicle, and where the event occurred between 06:00 and 23:00 day hours during 2012. Elimination criteria were incomplete case information, cyclists, motorcyclists or other non-pedestrian subjects involved and a modified road infrastructure after the event. The latter was established because, over the last 5 years in GMA, there have been a number of 
Table 1 Description of records excluded from FOMESE

\begin{tabular}{lc}
\hline & $\mathbf{n}(\%)$ \\
\hline Event mechanics* & $13(5.44)$ \\
\hline Other cause of death or non-pedestrian subject involved & \\
\hline \multicolumn{1}{l}{ Strangled } & $1(0.42)$ \\
\hline Died under beating & $1(0.42)$ \\
\hline Cyclist & $11(4.60)$ \\
\hline MVC & $23(9.62)$ \\
\hline Roll-over & $17(7.11)$ \\
\hline Motorcyclist & $7(2.93)$ \\
Outside of GMA & $30(12.55)$ \\
\hline Out of age range & $73(30.54)$ \\
\hline Out of established schedule & $23(9.62)$ \\
Insufficient data† & $39(16.32)$ \\
Lost record & $1(0.42)$ \\
\hline Total & $239(100.0)$ \\
\hline
\end{tabular}

*Refers to event kinematics in which the subject was ejected from the vehicle and was hit by a car.

tInsufficient data were the location, date and age.

FOMESE, Forensic Medical Service; GMA, Guadalajara Metropolitan Area.

modifications in the road system organisation; specifically, a new urban rail line and some road changes for cycling transportation inclusion, among other public works in the municipalities of GMA (Guadalajara, Zapopan, Tlaquepaque, Tonalá, Tlajomulco de Zuñiga, El Salto, Juanacatlán, Ixtlahuacán de los Membrillos).

It is worth mentioning that we created the schedule for the study based on the measurements of road sites, which were made at the same time that the event occurred and could also affect the researchers' personal safety in certain areas of GMA.

The measurements taken at the control locations were done at the same day and hour of the week in which the event took place. We did this in accordance with the registered data on the death certificate, with the goal of ensuring that the conditions of the road infrastructure and environmental interactions (ie, the same number of pedestrian flow or street vending stands) were similar to those present at the time of the transit events.

We obtained the data concerning the pedestrian mortality rate in GMA from the Forensic Medical Service (FOMESE). We also obtained the records of deaths caused by transit events with pedestrians involved, and these were verified to include the following information: age and sex of the pedestrian; collision location (street, intersection, neighbourhood and municipality, to obtain the geographical information); and date and time of the event. To confirm the reliability of the reported information, the intersection, neighbourhood and municipality were checked to match the map, and once the location was confirmed, the minimum mapping unit (MMU) was obtained using a digital map of Mexico, version 5.0

We used the spatial analysis theory ${ }^{9}{ }^{10}$ to select the control locations in the study based on the supposition that the proximity to the event location would ensure that the site characteristics were similar. In contrast to distant control locations, assuming that the characteristics would be different from those at the event site. Thus, the controls were selected randomly from intersections where no pedestrian deaths by motor vehicle collision had occurred with roads of the same hierarchy of the case, this characteristic was used as match criteria. In this study, we used a ratio 1:1 case-control based on this theory, one control near to the case and other control with the same street hierarchy but in a different location that could be far away from the case
Table 2 Characteristics of transit events with pedestrians involved in GMA, 2012

\begin{tabular}{|c|c|}
\hline Event distribution by municipality & n (\%) \\
\hline El Salto & $0(0.0)$ \\
\hline Guadalajara & $26(36.0)$ \\
\hline Tlajomulco de Zuñiga & $0(0.0)$ \\
\hline Tlaquepaque & $17(24.0)$ \\
\hline Tonalá & $10(14.0)$ \\
\hline Zapopan & $19(26.0)$ \\
\hline Zapotlanejo & $0(0.0)$ \\
\hline \multicolumn{2}{|l|}{ Sex of the pedestrian deceased } \\
\hline Male & $61(84.72)$ \\
\hline Female & $11(18.28)$ \\
\hline \multicolumn{2}{|l|}{ Age group (years) } \\
\hline$<20$ & $3(4.0)$ \\
\hline $20-29$ & $14(19.0)$ \\
\hline $30-39$ & $20(28.0)$ \\
\hline $40-49$ & $16(22.0)$ \\
\hline $50-59$ & $15(21.0)$ \\
\hline $60-65$ & $4(6.0)$ \\
\hline \multicolumn{2}{|l|}{ Time-lapse of the event (hours) } \\
\hline $6: 00-11: 59$ & $17(23.61)$ \\
\hline $12: 00-17: 59$ & 19 (26.39) \\
\hline $18: 00-23: 00$ & $36(50.00)$ \\
\hline \multicolumn{2}{|l|}{ Weekday of the event } \\
\hline Sunday & $11(15.28)$ \\
\hline Monday & $9(12.50)$ \\
\hline Tuesday & $14(19.44)$ \\
\hline Wednesday & $12(16.67)$ \\
\hline Thursday & $13(18.06)$ \\
\hline Friday & $7(9.72)$ \\
\hline Saturday & $6(8.33)$ \\
\hline \multicolumn{2}{|l|}{ Span of months } \\
\hline January to April & $19(26.39)$ \\
\hline May to August & $35(48.61)$ \\
\hline September to December & $18(25.00)$ \\
\hline \multicolumn{2}{|l|}{ Site of the public road } \\
\hline Road intersection & $71(98.0)$ \\
\hline Street narrowness & $1(2.0)$ \\
\hline Total & $72(100.0)$ \\
\hline
\end{tabular}

GMA, Guadalajara Metropolitan Area.

site. For this reason, the statistical analysis was done separated, case-near control and case-far control.

From the FOMESE data, we examined a total of 338 records of dead pedestrians during 2012, of these 239 were removed for presenting any of the exclusion criteria previously established (table 1). Later, from the 99 remaining records, 18 were excluded because the exact location could not be extracted from the data described. At the end of the selection process, 72 records were classified as cases.

For controls definition, random intersections were selected in which no pedestrian deaths occurred due to motor vehicle collisions that had connecting roads of the same case hierarchy. Control selection for cases was made choosing two intersections: one with the same MMU where the event occurred and the other from an MMU chosen at random using a random numbers table. Initially, the study showed that there were important environmental differences between those cases in which the death occurred on the ring road in comparison to the selected controls 
Table 3 Other features of road intersection

\begin{tabular}{|c|c|c|c|c|c|c|c|c|c|c|}
\hline \multirow[b]{2}{*}{ Variable } & \multicolumn{2}{|c|}{ Case location } & \multicolumn{2}{|c|}{$\begin{array}{l}\text { Control location } \\
\text { (nearby) }\end{array}$} & \multirow[b]{2}{*}{ Mean difference } & \multirow[b]{2}{*}{$P$ value } & \multicolumn{2}{|c|}{$\begin{array}{l}\text { Control location } \\
\text { (distant) }\end{array}$} & \multirow[b]{2}{*}{ Mean difference } & \multirow[b]{2}{*}{$P$ value } \\
\hline & $\mu$ & $\mathrm{DE}$ & $\mu$ & $\mathrm{DE}$ & & & $\mu$ & $\mathrm{DE}$ & & \\
\hline Traffic flow & 299.31 & 241.79 & 123.82 & 194.72 & $175.49(103.17,247.81)$ & $<0.001$ & 98.12 & 107.20 & $201.19(139.33,263.05)$ & $<0.001$ \\
\hline Pedestrian flow & 18.65 & 15.15 & 9.04 & 7.21 & $9.61(5.70,13.52)$ & $<0.001$ & 11 & 8.52 & $7.65(3.59,11.71)$ & $<0.001$ \\
\hline Parked cars & 11.39 & 10.97 & 12.28 & 10.79 & -0 to $89(-4.47,2.69)$ & $<0.001$ & 12.76 & 12.28 & $-1.37(-5.21,2.47)$ & $>0.05$ \\
\hline Sidewalk width & 3.15 & 2.46 & 2.03 & 1.47 & $1.12(0.45,1.79)$ & $>0.05$ & 2.27 & 1.86 & $0.88(0.16,1.60)$ & $<0.01$ \\
\hline
\end{tabular}

$\mu$ denotes mean; $D E$ denotes standard desviation.

with the aforementioned process. To avoid this selection bias, we modified the selection process for controls for all pedestrian fatalities that took place on the ring road by considering differing features such as width, vehicle flow, road signs and speed limit.

First, of the 1670 MMUs from GMA, we identified 71 that constitute the ring road. From these, an MMU was selected for controls. Next, the intersections from the MMU were enumerated, starting from the upper left corner and continuing unto the right side. After that, we selected the intersection using the random numbers table and picked two controls.

Of the remaining 1599 MMUs, controls were taken for those cases that occurred anywhere else, excluding the ring road. On these, it was possible to choose a control from the same MMU where the case occurred, and the other from a randomly chosen MMU. Afterward, the control intersections from both MMUs were enumerated from west to east and north to south to randomly select the intersection for the study.

The road system features analysed were: road geometric design, signage, infrastructure (bus stops, traffic lights, speed reducers) and the pedestrian subsystem (pedestrian crossing, pedestrian bridge and sidewalks). We considered traffic and pedestrian flow as intervening factors. They were calculated by number of vehicles or pedestrians transit on the intersection in any direction in $5 \mathrm{~min}$.

The statistical analysis was carried out in three stages: (1) means, SD, frequencies and percentages were obtained; and (2) a bivariate analysis was made to obtain OR with $95 \%$ CIs. In cases that were not feasible to obtain an OR, we would calculate a Fisher's exact test with a statistical significance of $\mathrm{p} \leq 0.05$. The logistic regression was made considering all variables with $p$ value $<0.25$ during the bivariate analysis. The model was done as saturated model and each variable was evaluated with partial $F$ test to analyse its contribution to the model, if $\mathrm{p}$ value was $>0.05$, the variables were eliminated from the model. Finally, the selected variables for the model were those with $p \leq 0.05$. In this model, we did not find any interaction. This analysis was made using IBM SPSS (V.20.0.0).

\section{RESULTS}

Pedestrian fatalities occurred mainly in the Guadalajara (36.0\%) and Zapopan (26.0\%) municipalities. Most of them took place between 18:00 and 23:00 hours (48.61\%), from Tuesday to Thursday (54.17\%), between May and August (48.61\%) and located at an intersection (98.0\%). Dead pedestrians were mostly men on a 5.5:1 ratio and older than 30 years $(76.0 \%)$ (table 2).

When comparing the road features where collisions took place with other locations in the same MMU, it was found that the traffic flow $(p \leq 0.001)$, pedestrian flow $(p \leq 0.001)$, number of parked cars $(p \leq 0.001)$, road width $(p \leq 0.05)$ and island width $(\mathrm{p} \leq 0.01)$ were statistically significant. In general, higher numbers were obtained on locations with dead pedestrians. Also, locations with different MMU were in similar conditions, excepting the number of parked cars and road width (table 3).

In the adjusted analysis, road features associated with pedestrian mortality on locations near to the case location were bus stops on both streets (adjusted OR (aOR) 6.80, 95\% CI 2.00 to 23.07 ) or on one street (aOR 9.18, 95\% CI 3.54 to 23.84), the presence of a pedestrian island (aOR 4.45, 95\% CI 1.85 to 10.74), a sidewalk wider than $3 \mathrm{~m}$ (aOR 3.24, 95\% CI 1.35 to 7.76), traffic flow $\geq 260$, vehicles (aOR 15.35 , 95\% CI 1.84 to 127.9) and pedestrian flow $\geq 14$ subjects (aOR 5.22, 95\% CI 2.09 to 13.07 ) (table 4).

On the locations outside of the MMU with a road system similar to that of the case, a risk of fatality was found on bus stops that were on both streets (aOR 6.5, 95\% CI 1.81 to 23.36), on one street (aOR 2.56, 95\% CI 1.61 to 5.68 ), the existence of a pedestrian island (aOR 2.93, 95\% CI 1.33 to 6.46) and traffic flow $\geq 260$ vehicles (aOR 3.72, 95\% CI 1.06 to 13.09 ). Additionally, we also found some risk-diminishing features of the road system: a vertical stop sign (aOR 0.19 , 95\% CI 0.06 to 0.63 ), crosswalks on both streets (aOR 0.19 , 95\% CI 0.08 to 0.49 ) or in one street (aOR $0.28,95 \%$ CI 0.10 to 0.76 ) (table 5).

\section{DISCUSSION}

According to the urban network theory and multiple connectivity theory, the last elements resulted as a risk factor due to a fault in connectivity between nodes. This could be explained because pedestrians tend to walk in a straight line towards their destination, therefore, the bus stop locations concerning businesses, schools, and alike have an influence on the expected behaviour of the pedestrians at the time of crossing the street and, as a consequence, the likelihood of death after a collision.

The protective factors for pedestrian mortality were only found in distant locations from the collision. These elements were marked crosswalks on one or both streets on intersections, the vertical stop signs and the number of parked vehicles, which ranged from 6 to 15 cars on the road. This agrees with the premise from the spatial analysis theory and explains why, for nearby controls, the marked crosswalks were not as significant as the protective factors. ${ }^{11}$

The marked crosswalk was a controversial element in carpedestrian collisions since some studies reported it as risk factor while others revealed it as a protective factor, and finally, because it did not show any significant association to pedestrian deaths. In support of this study, similar results were obtained in Maine, Vancouver and Düsseldorf. ${ }^{12-14}$ Furthermore, in California, the presence of marked crosswalks represented a risk increment of two times more, and another study conducted in Washington reported this element as a risk factor. ${ }^{15}$ It has even been mentioned that this risk increase is due to a false sense of security 
Table 4 Factors related to road system organisation and its association with mortality due to motor vehicle-pedestrian collisions in Guadalajara Metropolitan Area, 2012

\begin{tabular}{|c|c|c|c|c|c|c|c|c|}
\hline \multirow[b]{2}{*}{ Road system } & \multicolumn{2}{|c|}{ Case location } & \multicolumn{2}{|c|}{ Control location (nearby) } & \multicolumn{2}{|c|}{ Bivariate analysis } & \multicolumn{2}{|c|}{ Multivariate analysis } \\
\hline & $\mathrm{n}$ & $\%$ & $\mathrm{n}$ & $\%$ & OR & $(95 \% \mathrm{Cl})$ & $\mathrm{aOR}$ & $95 \% \mathrm{Cl}$ \\
\hline \multicolumn{9}{|l|}{ Intersection features } \\
\hline \multicolumn{9}{|l|}{ Intersection } \\
\hline$T$ & 27 & 37.50 & 28 & 38.90 & 1.01 & 0.48 to 2.12 & - & - \\
\hline Cross & 40 & 55.60 & 42 & 58.30 & 1 & & - & - \\
\hline \multicolumn{9}{|l|}{ Ways* } \\
\hline Four & 51 & 10.80 & 34 & 47.20 & 2.41 & 0.82 to 7.50 & - & - \\
\hline Three & 13 & 18.10 & 25 & 34.70 & 0.84 & 0.24 to 3.00 & - & - \\
\hline Two & 8 & 11.10 & 13 & 18.10 & 1 & & & \\
\hline \multicolumn{9}{|l|}{ Pot-holes } \\
\hline In both streets & 8 & 11.10 & 17 & 23.60 & 0.47 & 0.15 to 1.32 & - & - \\
\hline In one street & 26 & 36.10 & 17 & 23.60 & 1.52 & 0.67 to 3.52 & - & - \\
\hline None & 38 & 52.80 & 38 & 52.80 & 1 & & & \\
\hline \multicolumn{9}{|c|}{ Intersection infrastructure } \\
\hline \multicolumn{9}{|l|}{ Bus stops } \\
\hline On both streets & 17 & 23.62 & 5 & 6.94 & 10.77 & 3.58 to 33.30 & 6.80 & 2.00 to 23.07 \\
\hline On one street & 37 & 51.39 & 10 & 13.89 & 11.72 & 4.88 to 28.16 & 9.18 & 3.54 to 23.84 \\
\hline None & 18 & 25.00 & 57 & 79.17 & 1.00 & & & \\
\hline \multicolumn{9}{|l|}{ Pedestrian bridge } \\
\hline Yes & 18 & 25.00 & 4 & 5.56 & 5.67 & 1.81 to 17.73 & 3.16 & 0.95 to 10.50 \\
\hline No & 54 & 75.00 & 68 & 94.40 & 1 & & & \\
\hline \multicolumn{9}{|l|}{ Speed bump } \\
\hline On both streets & 0 & 0.00 & 0 & 0.00 & & & & \\
\hline On one street & 4 & 5.6 & 11 & 15.30 & 0.32 & 0.07 to 1.18 & - & - \\
\hline None & 68 & 94.40 & 61 & 84.70 & 1 & & - & - \\
\hline \multicolumn{9}{|l|}{ Road signs } \\
\hline \multicolumn{9}{|c|}{ Stop signs (horizontal) } \\
\hline On both streets & 5 & 6.90 & 3 & 4.20 & 1.72 & 0.31 to 11.75 & - & - \\
\hline On one street & 20 & 27.80 & 20 & 27.80 & 1.04 & 0.46 to 2.33 & - & - \\
\hline None & 47 & 65.30 & 49 & 68.10 & 1 & & & \\
\hline \multicolumn{9}{|c|}{ Stops signs (vertical) } \\
\hline On both streets & 0 & 0.00 & 0 & 0.00 & & & & \\
\hline On one street & 4 & 5.60 & 11 & 15.30 & 0.32 & 0.07 to 1.18 & - & - \\
\hline None & 68 & 94.40 & 61 & 84.70 & 1 & & - & - \\
\hline \multicolumn{9}{|l|}{ Lane markings } \\
\hline Marked & 43 & 59.90 & 27 & 37.5 & 2.45 & 1.2 to 5.10 & - & - \\
\hline Not marked & 29 & 40.30 & 45 & 62.50 & 1 & & - & - \\
\hline Directional arrows & & & & & & & & \\
\hline Marked & 20 & 27.80 & 17 & 23.30 & 1.79 & 0.84 to 3.92 & - & - \\
\hline Not marked & 52 & 72.30 & 55 & 76.40 & 1 & & - & - \\
\hline Speed limit & & & & & & & & \\
\hline Marked & 8 & 11.20 & 5 & 7.00 & 1.66 & 0.45 to 6.84 & - & - \\
\hline Not marked & 64 & 88.90 & 67 & 93.10 & 1 & & - & - \\
\hline Pedestrian subsystem & & & & & & & & \\
\hline Crosswalks & & & & & & & & \\
\hline On both streets & 18 & 25.00 & 16 & 22.20 & 1.12 & 0.46 to 2.72 & - & - \\
\hline On one street & 14 & 19.40 & 16 & 22.20 & 0.87 & 0.34 to 2.20 & - & - \\
\hline None & 40 & 55.60 & 40 & 55.60 & 1 & & & \\
\hline Cars parked on the & & & & & & & & \\
\hline On both streets & 12 & 16.70 & 6 & 8.30 & 2.64 & 0.82 to 9.44 & - & - \\
\hline On one street & 24 & 33.30 & 18 & 25.00 & 1.77 & 0.78 to 4.03 & - & - \\
\hline None & 36 & 50.00 & 48 & 66.70 & 1 & & & \\
\hline Street vending & & & & & & & & \\
\hline On both streets & 8 & 11.10 & 4 & 5.60 & 2.52 & 0.62 to 12.31 & - & - \\
\hline On one street & 24 & 33.30 & 17 & 23.60 & 1.79 & 0.80 to 4.08 & - & - \\
\hline
\end{tabular}




\section{Original research}

Table 4 Continued

\begin{tabular}{|c|c|c|c|c|c|c|c|c|}
\hline \multirow[b]{2}{*}{ Road system } & \multicolumn{2}{|c|}{ Case location } & \multicolumn{2}{|c|}{ Control location (nearby) } & \multicolumn{2}{|c|}{ Bivariate analysis } & \multicolumn{2}{|c|}{ Multivariate analysis } \\
\hline & $\mathrm{n}$ & $\%$ & $\mathrm{n}$ & $\%$ & OR & $(95 \% \mathrm{Cl})$ & aOR & $95 \% \mathrm{Cl}$ \\
\hline None & 40 & 55.60 & 51 & 70.80 & 1 & & & \\
\hline \multicolumn{9}{|l|}{ Continuous sidewalk } \\
\hline On both streets & 43 & 59.70 & 42 & 58.30 & 1.56 & 0.67 to 3.70 & - & - \\
\hline On one street & 14 & 19.40 & 7 & 9.70 & 3.00 & 0.88 to 11.07 & - & - \\
\hline Non-continuous & 15 & 20.80 & 23 & 31.90 & 1 & & & \\
\hline \multicolumn{9}{|c|}{ Cracked, broken or irregular sidewalks } \\
\hline On both streets & 33 & 45.80 & 31 & 43.10 & 1.62 & 0.64 to 4.22 & - & - \\
\hline On one street & 26 & 36.10 & 21 & 29.20 & 1.88 & 0.70 to 5.21 & - & - \\
\hline None & 13 & 18.10 & 20 & 27.80 & 1 & & & \\
\hline \multicolumn{9}{|l|}{ Road infrastructure } \\
\hline \multicolumn{9}{|l|}{ Traffic light } \\
\hline Yes & 25 & 34.72 & 11 & 15.28 & 2.95 & 1.32 to 6.60 & 2.02 & 0.82 to 4.9 \\
\hline No & 47 & 65.28 & 61 & 84.72 & 1.00 & & 1.00 & \\
\hline \multicolumn{9}{|l|}{ Pedestrian island } \\
\hline Yes & 36 & 50.00 & 10 & 13.89 & 6.20 & 2.75 to 13.97 & 4.45 & 1.85 to 10.74 \\
\hline No & 36 & 50.00 & 62 & 86.11 & 1.00 & & 1.00 & \\
\hline \multicolumn{9}{|l|}{ Sidewalk } \\
\hline$\geq 3 \mathrm{~m}$ & 35 & 48.61 & 15 & 20.83 & 4.02 & 1.74 to 9.30 & 3.24 & 1.35 to 7.76 \\
\hline$>1.7 \mathrm{~m}$ to $<3 \mathrm{~m}$ & 19 & 26.39 & 26 & 36.11 & 1.26 & 0.55 to 2.88 & 1.11 & 0.47 to 2.64 \\
\hline$\leq 1.7 \mathrm{~m}$ & 18 & 25.00 & 31 & 43.06 & 1.00 & & 1.00 & \\
\hline \multicolumn{9}{|l|}{ Road features } \\
\hline \multicolumn{9}{|l|}{ Road hierarchy $\dagger$} \\
\hline Arterial & 26 & 36.10 & 7 & 9.70 & 2.10 & 0.68 to 7.06 & - & - \\
\hline Collector & 7 & 9.70 & 4 & 5.60 & 1 & 0.21 to 5.40 & - & - \\
\hline Minor collector & 5 & 6.90 & 10 & 13.90 & 0.29 & 0.06 to 1.13 & - & - \\
\hline Subcollector & 5 & 6.90 & 9 & 12.50 & 0.32 & 0.07 to 1,29 & - & - \\
\hline Local & 1 & 1.4 & 26 & 36.10 & 0.02 & 0.001 to 0.17 & - & - \\
\hline Access to property & 28 & 38.90 & 16 & 22.20 & 1 & & & \\
\hline \multicolumn{9}{|l|}{ Road materials } \\
\hline Cobble & 1 & 1.40 & 2 & 2.80 & 0.44 & 0.01 to 8,86 & - & - \\
\hline Concrete & 27 & 37.50 & 22 & 30.60 & 1.08 & 0.49 to 2.35 & - & - \\
\hline Paving stone & 1 & 1.40 & 8 & 11.10 & 0.11 & 0.002 to 0.90 & - & - \\
\hline Dirt & 1 & 1.40 & 3 & 4.20 & 0.29 & 0.005 to 3.89 & - & - \\
\hline Asphalt & 42 & 58.30 & 37 & 51.40 & 1 & & & \\
\hline \multicolumn{9}{|l|}{ Other road features } \\
\hline \multicolumn{9}{|l|}{ Road width } \\
\hline$\geq 28 \mathrm{~m}$ & 34 & 47.22 & 18 & 25.00 & 4.86 & 2.10 to 11.26 & 1.65 & 0.56 to 4.84 \\
\hline$>12$ to $<28 \mathrm{~m}$ & 24 & 33.33 & 18 & 25.00 & 3.33 & 1.37 to 7.96 & 1.79 & 0.63 to 5.08 \\
\hline$\leq 12 \mathrm{~m}$ & 14 & 19.44 & 35 & 48.61 & 1.00 & & 1.00 & \\
\hline \multicolumn{9}{|l|}{ Parked cars } \\
\hline$\geq 15$ & 26 & 36.11 & 24 & 33.33 & 0.86 & 0.39 to 1.87 & 0.49 & 0.19 to 1.23 \\
\hline$<15$ to $>6$ & 17 & 23.61 & 25 & 34.72 & 0.54 & 0.24 to 1.23 & 0.55 & 0.22 to 1.36 \\
\hline$\leq 6$ & 29 & 40.28 & 23 & 31.94 & 1.00 & & 1.00 & \\
\hline \multicolumn{9}{|l|}{ Traffic flow $\ddagger$} \\
\hline$\geq 260$ & 36 & 50.00 & 12 & 16.67 & 13.33 & 5.03 to 35.33 & 15.35 & 1.84 to 127.9 \\
\hline $35-259$ & 27 & 37.50 & 20 & 27.78 & 6.00 & 2.38 to 15.14 & 5.67 & 0.61 to 52.45 \\
\hline $0-34$ & 9 & 12.50 & 40 & 55.56 & 1.00 & & 1.00 & \\
\hline Pedestrian flow $\ddagger$ & & & & & & & & \\
\hline$\geq 14$ & 37 & 51.39 & 16 & 22.22 & 5.35 & 2.33 to 12.36 & 5.22 & 2.09 to 13.07 \\
\hline $8-13$ & 19 & 26.39 & 19 & 26.39 & 2.31 & 0.97 to 5.50 & 2.18 & 0.87 to 5.42 \\
\hline $0-7$ & 16 & 22.22 & 37 & 51.39 & 1.00 & & 1.00 & \\
\hline
\end{tabular}

In the multivariate analysis, the variables were adjusted among them.

*Refers to the direction of vehicles going north-south and vice versa, and east-west and vice versa; therefore, if these converge at an intersection, this is called four ways, and so forth.

tThe hierarchy is based on the road width, number of lanes and road capacity.

¥Estimated on a 5 min or 300 s lapse.

aOR, adjusted OR. 
Table 5 Factors related to road system organisation and its association with mortality due to motor vehicle-pedestrian collisions in Guadalajara Metropolitan Area, 2012

\begin{tabular}{|c|c|c|c|c|c|c|c|c|}
\hline \multirow[b]{2}{*}{ Road system } & \multicolumn{2}{|c|}{ Case location } & \multicolumn{2}{|c|}{ Control location (distant) } & \multicolumn{2}{|c|}{ Bivariate analysis } & \multicolumn{2}{|c|}{ Multivariate analysis } \\
\hline & $\mathrm{n}$ & $\%$ & $\mathrm{n}$ & $\%$ & OR & $(95 \% \mathrm{Cl})$ & $\mathrm{aOR}$ & $95 \% \mathrm{Cl}$ \\
\hline \multicolumn{9}{|l|}{ Intersection features } \\
\hline \multicolumn{9}{|l|}{ Intersection } \\
\hline T & 27 & 37.50 & 20 & 27.80 & 1.64 & 0.76 to 3.60 & - & - \\
\hline Cross & 40 & 55.60 & 49 & 68.10 & 1 & & - & - \\
\hline \multicolumn{9}{|l|}{ Ways* } \\
\hline Four & 51 & 10.80 & 41 & 56.90 & 2.77 & 1.02 to 816 & - & - \\
\hline Three & 13 & 18.10 & 13 & 18.10 & 2.21 & 0.63 to 8.19 & - & - \\
\hline Two & 8 & 11.10 & 18 & 25.00 & 1 & & & \\
\hline \multicolumn{9}{|l|}{ Pot-holes } \\
\hline In both streets & 8 & 11.10 & 10 & 13.90 & 0.96 & 0.29 to 0.03 & - & - \\
\hline In one street & 26 & 36.10 & 16 & 22.20 & 1.95 & 0.86 to 4.52 & - & - \\
\hline None & 38 & 52.80 & 46 & 63.90 & 1 & & & \\
\hline \multicolumn{9}{|c|}{ Intersection infrastructure } \\
\hline \multicolumn{9}{|l|}{ Bus stops } \\
\hline On both streets & 17 & 23.61 & 4 & 5.56 & 9.44 & 2.78 to 32.08 & 6.5 & 1.81 to 23.36 \\
\hline On one street & 37 & 51.39 & 28 & 38.89 & 2.94 & 1.40 to 6.17 & 2.56 & 1.61 to 5.68 \\
\hline None & 18 & 25.00 & 40 & 55.56 & 1.00 & & 1.00 & \\
\hline \multicolumn{9}{|l|}{ Pedestrian bridge } \\
\hline Yes & 18 & 25.00 & 72 & 100.0 & - & - & - & - \\
\hline No & 54 & 75.00 & 0 & 0.00 & - & - & - & - \\
\hline \multicolumn{9}{|l|}{ Speed bump } \\
\hline On both streets & 0 & 0.00 & 4 & 5.60 & & & & \\
\hline On one street & 4 & 5.6 & 7 & 9.70 & 0.51 & 0.10 to 2.14 & - & - \\
\hline None & 68 & 94.40 & 61 & 84.70 & 1 & & - & - \\
\hline \multicolumn{9}{|l|}{ Road signs } \\
\hline \multicolumn{9}{|c|}{ Stop signs (horizontal) } \\
\hline On both streets & 5 & 6.90 & 7 & 9.70 & 0.49 & 0.11 to 1.97 & - & - \\
\hline On one street & 20 & 27.80 & 33 & 45.80 & 0.41 & 0.46 to 2.33 & - & - \\
\hline None & 47 & 65.30 & 32 & 44.40 & 1 & & & \\
\hline \multicolumn{9}{|l|}{ Stops signs (vertical) } \\
\hline On both streets & 4 & 5.56 & 13 & 18.06 & 0.27 & 0.08 to 0.86 & 0.19 & 0.06 to 0.63 \\
\hline On one street & 68 & 94.44 & 59 & 81.94 & 1.00 & & 1.00 & \\
\hline \multicolumn{9}{|l|}{ Lane markings } \\
\hline Marked & 43 & 59.90 & 36 & 50.00 & 1.47 & 0.72 to 3.02 & - & - \\
\hline Not marked & 29 & 40.30 & 36 & 50.00 & 1 & & - & - \\
\hline Directional arrows & & & & & & & & \\
\hline Marked & 20 & 27.80 & 29 & 40.30 & 0.82 & 0.40 to 1.67 & - & - \\
\hline Not marked & 52 & 72.30 & 43 & 59.70 & 1 & & - & - \\
\hline Speed limit & & & & & & & & \\
\hline Marked & 8 & 11.20 & 12 & 16.70 & 0.62 & 0.20 to 1.8 & - & - \\
\hline Not marked & 64 & 88.90 & 60 & 83.30 & 1 & & - & - \\
\hline Pedestrian subsystem & & & & & & & & \\
\hline Crosswalks & & & & & & & & \\
\hline On both streets & 18 & 25.00 & 28 & 38.89 & 0.37 & 0.17 to 0.81 & 0.19 & 0.08 to 0.49 \\
\hline On one street & 14 & 19.44 & 21 & 29.17 & 0.38 & 0.16 to 0.89 & 0.28 & 0.10 to 0.76 \\
\hline None & 40 & 55.56 & 23 & 31.94 & 1.00 & & 1.00 & \\
\hline Cars parked on the & & & & & & & & \\
\hline On both streets & 12 & 16.70 & 5 & 6.90 & 2.90 & 0.85 to 11.53 & - & - \\
\hline On one street & 24 & 33.30 & 23 & 31.90 & 1.27 & 0.58 to 2.79 & - & - \\
\hline None & 36 & 50.00 & 44 & 61.10 & 1 & & & \\
\hline Street vending & & & & & & & & \\
\hline On both streets & 8 & 11.11 & 1 & 1.39 & 11.00 & 1.32 to 91.48 & 7.97 & 0.94 to 68.37 \\
\hline On one street & 14 & 19.44 & 16 & 22.22 & 2.06 & 0.97 to 4.38 & 1.37 & 0.60 to 3.14 \\
\hline None & 40 & 55.56 & 55 & 76.39 & 1.00 & & 1.00 & \\
\hline
\end{tabular}




\section{Original research}

Table 5 Continued

\begin{tabular}{|c|c|c|c|c|c|c|c|c|}
\hline \multirow[b]{2}{*}{ Road system } & \multicolumn{2}{|c|}{ Case location } & \multicolumn{2}{|c|}{ Control location (distant) } & \multicolumn{2}{|c|}{ Bivariate analysis } & \multicolumn{2}{|c|}{ Multivariate analysis } \\
\hline & $\mathbf{n}$ & $\%$ & $\mathbf{n}$ & $\%$ & OR & $(95 \% \mathrm{Cl})$ & $\mathrm{aOR}$ & $95 \% \mathrm{Cl}$ \\
\hline \multicolumn{9}{|l|}{ Continuous sidewalk } \\
\hline On both streets & 43 & 59.70 & 41 & 56.90 & 1.67 & 0.72 to 3.94 & - & - \\
\hline On one street & 14 & 19.40 & 7 & 9.70 & 3.13 & 0.92 to 11.51 & - & - \\
\hline Non-continuous & 15 & 20.80 & 24 & 33.30 & 1 & & & \\
\hline \multicolumn{9}{|c|}{ Cracked, broken or irregular sidewalks } \\
\hline On both streets & 33 & 45.80 & 25 & 34.70 & 2.31 & 0.91 to 6.04 & - & - \\
\hline On one street & 26 & 36.10 & 24 & 33.30 & 1.90 & 0.73 to 5.08 & - & - \\
\hline None & 13 & 18.10 & 23 & 31.90 & 1 & & & \\
\hline \multicolumn{9}{|l|}{ Road infrastructure } \\
\hline \multicolumn{9}{|l|}{ Traffic light } \\
\hline Yes & 25 & 34.72 & 22 & 30.56 & 1.21 & 0.60 to 2.43 & 0.86 & 0.40 to 1.87 \\
\hline No & 47 & 65.28 & 50 & 69.44 & 1.00 & & 1.00 & \\
\hline \multicolumn{9}{|l|}{ Pedestrian island } \\
\hline Yes & 36 & 50.00 & 15 & 20.83 & 3.80 & 1.82 to 7.91 & 2.93 & 1.33 to 6.46 \\
\hline No & 39 & 50.00 & 57 & 69.44 & 1.00 & & 1.00 & \\
\hline \multicolumn{9}{|l|}{ Sidewalk } \\
\hline$\geq 3 \mathrm{~m}$ & 35 & 48.61 & 25 & 34.72 & 2.26 & 1.03 to 4.92 & 1.99 & 0.90 to 4.41 \\
\hline$>1.7 \mathrm{~m}$ to $<3 \mathrm{~m}$ & 19 & 26.39 & 15 & 20.83 & 1.70 & 0.71 to 4.07 & 1.94 & 0.78 to 4.81 \\
\hline$\leq 1.7 \mathrm{~m}$ & 18 & 25.00 & 32 & 44.44 & 1.00 & & 1.00 & \\
\hline \multicolumn{9}{|l|}{ Road features } \\
\hline \multicolumn{9}{|l|}{ Road hierarchyt } \\
\hline Arterial & 26 & 36.10 & 7 & 9.70 & 2.23 & 0.73 to 7.45 & - & - \\
\hline Collector & 7 & 9.70 & 13 & 18.10 & 0.33 & 0.09 to 1.10 & - & - \\
\hline Minor collector & 5 & 6.90 & 7 & 9.70 & 0.44 & 0.09 to 1.90 & - & - \\
\hline Subcollector & 5 & 6.90 & 13 & 18.10 & 0.23 & 0.06 to 0.87 & - & - \\
\hline Local & 1 & 1.4 & 15 & 20.80 & 0.04 & 0.001 to 0.32 & - & - \\
\hline Access to property & 28 & 38.90 & 17 & 23.60 & 1 & & & \\
\hline \multicolumn{9}{|l|}{ Road materials } \\
\hline Cobble & 1 & 1.40 & 0 & 0.00 & & & & \\
\hline Concrete & 27 & 37.50 & 21 & 29.20 & 1.28 & 0.59 to 2.79 & - & - \\
\hline Paving stone & 1 & 1.40 & 6 & 8.30 & 0.16 & 0.003 to 1.48 & - & - \\
\hline Dirt & 1 & 1.40 & 3 & 4.20 & 0.33 & 0.01 to 4.39 & - & - \\
\hline Asphalt & 42 & 58.30 & 42 & 58.30 & 1 & & & \\
\hline \multicolumn{9}{|l|}{ Other road features } \\
\hline \multicolumn{9}{|l|}{ Road width } \\
\hline$\geq 28 \mathrm{~m}$ & 34 & 47.22 & 19 & 26.39 & 4.47 & 1.94 to 10.32 & 2.24 & 0.81 to 6.20 \\
\hline$>12$ to $<28 m$ & 24 & 33.33 & 18 & 25.00 & 3.33 & 1.37 to 7.96 & 1.79 & 0.63 to 5.08 \\
\hline$\leq 12 \mathrm{~m}$ & 14 & 19.44 & 35 & 48.61 & 1.00 & & 1.00 & \\
\hline \multicolumn{9}{|l|}{ Parked cars } \\
\hline$\geq 15$ & 26 & 36.11 & 28 & 38.89 & 0.67 & 0.31 to 1.46 & 0.41 & 0.16 to 1.06 \\
\hline$<15$ to $>6$ & 17 & 23.61 & 23 & 31.94 & 0.53 & 0.23 to 1.24 & 0.39 & 0.16 to 0.96 \\
\hline$\leq 6$ & 29 & 40.28 & 21 & 29.17 & 1.00 & & 1.00 & \\
\hline \multicolumn{9}{|l|}{ Traffic flow $\ddagger$} \\
\hline$\geq 260$ & 36 & 50.00 & 7 & 9.72 & 20.00 & 6.71 to 59.59 & 3.72 & 1.06 to 13.09 \\
\hline $35-259$ & 27 & 37.50 & 30 & 41.67 & 3.50 & 1.43 to 8.59 & 1.31 & 0.29 to 6.02 \\
\hline $0-34$ & 9 & 12.50 & 35 & 48.61 & 1.00 & & 1.00 & \\
\hline \multicolumn{9}{|l|}{ Pedestrian flow $\ddagger$} \\
\hline$\geq 14$ & 37 & 51.39 & 23 & 31.94 & 2.41 & 1.06 to 5.47 & 1.78 & 0.72 to 4.42 \\
\hline $8-13$ & 19 & 26.39 & 25 & 34.72 & 1.14 & 0.48 to 2.72 & 0.93 & 0.37 to 2.36 \\
\hline $0-7$ & 16 & 22.22 & 24 & 33.33 & 1.00 & & 1.00 & \\
\hline
\end{tabular}

In the multivariate analysis, the variables were adjusted among them.

* Refers to the direction of vehicles going north-south and vice versa, and east-west and vice versa; therefore, if these converge at an intersection, this is called four ways, and so forth.

tThe hierarchy is based on the road width, number of lanes and road capacity.

¥Estimated on a 5 min or $300 \mathrm{~s}$ lapse.

aOR, adjusted OR. 
when using marked crosswalks, ${ }^{16}$ though opposite results were obtained in Chapel Hill, North Carolina, ${ }^{11}$ where no statistical association was reported.

The road signs in a study done in North Carolina ${ }^{17}$ showed a risk reduction of being hit by a car. The same result was obtained in this study. However, this is different from what was found in a study done in Northeast Washington, ${ }^{18}$ where no statistical association was found between road signs. It was found that parked cars were a reducing risk factor, in contrast to what was reported in Auckland ${ }^{19}$ and in the Southwestern United States. ${ }^{20}$

As in other studies, ${ }^{1321-23}$ the presence of bus stops was shown to be a risk factor in car-pedestrian collisions. In contrast, in another study, no statistical association was shown. ${ }^{11}$ On the other hand, the presence of speed bumps ${ }^{24}$ was reported as a protective factor, in contrast to this study, where we did not find any significant association.

In our study, we observed that the pedestrian island did not have all the ideal features for pedestrian safety, in contrast to a study conducted in Flanders, Belgium. ${ }^{25}$ This contrast could be due to the planning and features of the street. The presence of the pedestrian island has shown a reduction in car-pedestrian collisions ${ }^{1326}$; however, in the present study, this increased the risk of death. The increase of vehicle traffic flow increased the risk of car-pedestrian collisions, as reported in other studies. ${ }^{18} 1922$ 27-34

The next factors that increased the risk of dying from a carpedestrian collision were only significant in nearby locations. These factors were the pedestrian traffic flow, in concordance with other studies, ${ }^{20} 21$ and width sidewalks. These results are similar to what was reported by Mueller et al, ${ }^{18}$ while contrasting with McMahon et al ${ }^{27}$ and Constant and Lagarde, ${ }^{26}$ who reported this latter as a protective factor. With this study, we do not explain the causes or mechanisms of why the width of sidewalks increases the risk, though this could be due to the interactions between various road system features.

The road system features without significant statistical association were the hierarchy of streets, the road width and lane markings. A number of researchers have studied the hierarchy of streets in Canada, ${ }^{13}$ England $^{35}$; North Carolina, USA ${ }^{17}$; and South Africa, ${ }^{36}$ with all of them concluding that there is a directly proportional relationship between road hierarchy and the risk of car-pedestrian collisions. The road width as a continuous variable was also an element that increased the mortality in car-pedestrian collisions in Washington, ${ }^{18}$ Maine,${ }^{12}$ Florida, ${ }^{37}$ England ${ }^{35}$ and Long Beach. ${ }^{38}$ The only study that obtained results similar to our study was Schneider and colleagues. ${ }^{11}$ Finally, Donroe $e^{2} a^{29}$ concluded that the lack of lane markings increased the risk of car-pedestrian collisions.

The advantages of this study are that it allows the identification of the elements of the road system that have an influence on pedestrian mortality in one of the biggest metropolitan areas in Mexico. Furthermore, this study involved other variables that had not been previously included in the literature. This is because these types of events are regularly analysed from the perspectives of either the pedestrian or the involved vehicle while location characteristics are often overlooked. Regarding the case-control methodology, in which the cases were the locations with pedestrian fatalities and the controls being locations without fatalities due to car-pedestrian collisions, a disadvantage was not considering other variables for matching, such as vehicle traffic flow or pedestrian traffic flow. Other limitations are that some variables were measured as categorical variables instead of numerical variables, also not considering pedestrian characteristics such as if they had a physical disability, the use of electronic devices or using alcohol or drugs.

\section{What is already known on the subject}

- These types of events are regularly analysed from the perspective of either the pedestrian or the involved vehicle while location characteristics are often overlooked.

\section{What this study adds}

- This study shows a different methodological option because the cases and controls are locations, not persons.

- In addition, it allows the identification of the elements of the road system that have an influence on pedestrian mortality in one of the biggest metropolitan areas in Mexico.

Funding The authors have not declared a specific grant for this research from any funding agency in the public, commercial or not-for-profit sectors.

Competing interests None declared.

Patient consent for publication Not required.

Provenance and peer review Not commissioned; internally peer reviewed.

Data sharing statement All data relevant to the study are included in the article or uploaded as supplementary information.

Open access This is an open access article distributed in accordance with the Creative Commons Attribution Non Commercial (CC BY-NC 4.0) license, which permits others to distribute, remix, adapt, build upon this work non-commercially, and license their derivative works on different terms, provided the original work is properly cited, appropriate credit is given, any changes made indicated, and the use is non-commercial. See: http://creativecommons.org/licenses/by-nc/4.0/.

\section{ORCID iD}

Ana Cecilia Mendez-Magaña http://orcid.org/0000-0002-4682-131X

\section{REFERENCES}

1 INEGI. Principales causas de mortalidad POR residencia habitual, grupos de edad Y sexo del fallecido. Tabulados básicos. Available: http://www.inegi.org.mx/est/ contenidos/proyectos/registros/vitales/mortalidad/tabulados/PC.asp?t=14\&c=11817 [Accessed 3 Jul 2018]

2 Salud Sde. Perfil nacional Y perfiles estatales de seguridad vial 2016. gob.mx, 2016. Available: http://www.gob.mx/salud/documentos/perfil-nacional-y-perfiles-estatalesde-seguridad-vial-2016? state=published [Accessed 16 Aug 2018].

3 Salud Sde. Perfil nacional Y perfiles estatales de seguridad vial. gob.mx, 2017. Available: http://www.gob.mx/salud/documentos/perfil-nacional-y-perfiles-estatalesde-seguridad-vial-118889?state=published [Accessed 16 Aug 2018].

4 Fuentes CM, Hernández V. La estructura espacial Urbana Y La incidencia de accidentes de tránsito en Tijuana, Baja California (2003-2004). Frontera norte 2009;21:109-38.

5 Salingaros NA. Principles of urban structure. Design/Science/Planning. Techne Press 2005.

6 Salingaros NA. Complexity and urban coherence. J Urban Des 2000;5:291-316.

7 Salingaros AN. Connecting the fractal city, 2003.

8 Matthew Levinson D, Huang A. A positive theory of network connectivity. 39. University of Minnesota: Nexus Research Group, Working Papers, 2010.

9 Díaz MC, Díaz JF, Ferreiro I, et al. Influencia de la geometría en La determinación de Los puntos de conflicto en Una intersección de viales, 2002. Available: https:// personal.ua.es/es/roberto-tomas/documentos/influencia-de-la-geometria-en-puntosde-conflicto-de-intersecciones-ingegraf-badajoz.pdf

10 Buzai G. Sistemas de Información Geográfica: aspectos conceptuales desde La teoría de la Geografía. Buenos Aires, Argentina: Sociedad Iberoamericana de Sistemas de Información Geográfica, 2007.

11 Schneider RJ, Ryznar RM, Khattak AJ. An accident waiting to happen: a spatial approach to proactive pedestrian planning. Accident Analysis \& Prevention 2004;36:193-211.

12 Gårder PE. The impact of speed and other variables on pedestrian safety in Maine. Accid Anal Prev 2004;36:533-42.

13 Schuurman N, Cinnamon J, Crooks VA, et al. Pedestrian injury and the built environment: an environmental scan of hotspots. BMC Public Health 2009;9.

14 von KR, Kohne C, Böhm 0, et al. Road injuries in school age children: relation to environmental factors amenable to interventions. Injury Prevention 1998;4:103-5.

15 Koepsell Tet al. Crosswalk markings and the risk of pedestrian-motor vehicle collisions in older pedestrians. JAMA 2002;288:2136-43. 


\section{Original research}

16 Peek-Asa C, Zwerling C. Role of environmental interventions in injury control and prevention. Epidemiologic Reviews 2003;25:77-89.

17 Kim J-K, Ulfarsson GF, Shankar VN, et al. A note on modeling pedestrian-injury severity in motor-vehicle crashes with the mixed logit model. Accident Analysis \& Prevention 2010;42:1751-8.

18 Mueller BA, Rivara FP, Lii SM, et al. Environmental factors and the risk for childhood pedestrian-motor vehicle collision occurrence. Am J Epidemiol 1990;132:550-60.

19 Roberts I, Norton R, Jackson R, et al. Effect of environmental factors on risk of injury of child pedestrians by motor vehicles: a case-control study. BMJ 1995;310:91-4.

20 Agran PF, Winn DG, Anderson CL, et al. Family, social, and cultural factors in pedestrian injuries among Hispanic children. Inj Prev 1998;4:188-93.

21 Pulugurtha SS, Sambhara VR. Pedestrian crash estimation models for signalized intersections. Accid Anal Prev 2011;43:439-46.

22 Hess P, Moudon A, Matlick J. Pedestrian safety and transit corridors. J Public Trans 2004;7:73-93.

23 Clifton KJ, Burnier CV, Akar G. Severity of injury resulting from pedestrian-vehicle crashes: what can we learn from examining the built environment? Transp Res D Transp Environ 2009;14:425-36.

24 Tester JM, Rutherford GW, Wald Z, et al. A matched case-control study evaluating the effectiveness of speed Humps in reducing child pedestrian injuries. Am J Public Health 2004;94:646-50.

25 Daniels $\mathrm{S}$, Brijs T, Nuyts $\mathrm{E}$, et al. Explaining variation in safety performance of roundabouts. Accid Anal Prev 2010;42:393-402.

26 Constant A, Lagarde E. Protecting vulnerable road users from injury. PLoS Med 2010;7:e1000228.

27 McMahon P, Duncan C, Stewart J, et al. Analysis of Factors Contributing to "Walking Along Roadway" Crashes. Transportation Research Record: Journal of the Transportation Research Board 1999:1674:41-8.
28 Berhanu G. Models relating traffic safety with road environment and traffic flows on arterial roads in Addis Ababa. Accid Anal Prev 2004;36:697-704.

29 Donroe J, Tincopa M, Gilman RH, et al. Pedestrian road traffic injuries in urban Peruvian children and adolescents: case control analyses of personal and environmental risk factors. PLoS One 2008;3:e3166.

30 Lascala EA, Gerber D, Gruenewald PJ. Demographic and environmental correlates of pedestrian injury collisions: a spatial analysis. Accid Anal Prev 2000;32:651-8.

31 LaScala EA, Gruenewald PJ, Johnson FW. An ecological study of the locations of schools and child pedestrian injury collisions. Accid Anal Prev 2004;36:569-76.

32 Roberts I, Crombie I. Child pedestrian deaths: sensitivity to traffic volume--evidence from the USA. J Epidemiol Community Health 1995;49:186-8.

33 Wier M, Weintraub J, Humphreys EH, et al. An area-level model of vehicle-pedestrian injury collisions with implications for land use and transportation planning. Accid Anal Prev 2009;41:137-45.

34 Roberts I, Marshall R, Norton R. Child pedestrian mortality and traffic volume in New Zealand. BMJ 1992;305

35 Graham DJ, Glaister S. Spatial variation in road pedestrian casualties: the role of urban scale, density and land-use mix, spatial variation in road pedestrian casualties: the role of urban scale, density and land-use mix. Urban Studies 2003;40:1591-607.

36 Hobday MB, Knight S. Motor vehicle collisions involving adult pedestrians in eThekwini in 2007. Int J Inj Contr Saf Promot 2010;17:61-8.

37 Abdel-Aty M, Chundi SS, Lee C. Geo-spatial and log-linear analysis of pedestrian and bicyclist crashes involving school-aged children. J Safety Res 2007;38:571-9.

38 Lightstone ASet al. A geographic analysis of motor vehicle collisions with child pedestrians in Long Beach, California: comparing intersection and midblock incident locations. Inj Prev 2001;7:155-60. 